\section{Fraction Learners: Assessing Understanding through Language Acquisition}

\author{
Michael J. Bosséa, Anass Bayaga ${ }^{\mathrm{b}, *}$, Catherine Fountainc, \\ Kathleen Lynch-Davis ${ }^{d}$, Ron Prestone, Kwaku Adu-Gyamfif
}

$\begin{array}{ll}\text { Received: } & \text { 14 September } 2018 \\ \text { Revised: } & 10 \text { November } 2018 \\ \text { Accepted: } & 16 \text { November } 2018 \\ \text { ISSN: 1307-9298 } \\ \text { Copyright @ IEJEE } \\ \text { www.iejee.com }\end{array}$

DOI: $10.26822 /$ iejee.2019248585

\begin{abstract}
This study applies the Mathematics Acquisition Framework (MAF) (Bossé, Ringler, Bayaga, Fountain, \& Young, 2018) to investigate fifth- through seventh-grade students' comprehension of fractions and decimals and examines how students build understanding of mathematical principles and concepts regarding fractions and decimals. Based on case studies and discourse analysis, the results revealed students in different stages of the MAF with some students employing informal/social language in their mathematical communication and others using formal/academic language. Additionally, mathematically erroneous student communication was more positively interpreted through the lens of the MAF, which interpreted student errors, misunderstandings, and miscommunications as natural components to learning.
\end{abstract}

Keywords: Fractions, Language Acquisition, Mathematics Understanding, Middle Grades

\section{Introduction}

Over the decades, a generous body of literature has evolved in each of the distinct fields of mathematics learning (e.g., Kara \& Incikabı, 2018; Biggs \& Collis, 1982; Burger \& Shaughnessy, 1986; Clements, Battista, \& Sarama, 2001; Dienes,1960, 1971; Dienes \& Golding, 1971; Van Hiele, 1986) and second language acquisition (SLA) (e.g., Chomsky, 1957, 1959, 1964; Krashen \& Terrell, 1983; Vygotsky, 1978). Although much has developed in these fields regarding explaining student thinking and learning, the literature in these realms have, until quite recently, remained mostly distinct. Additionally, scant research has attempted to see how or whether these fields speak to, or complement, each other.

In response to the scant research addressing the possible intersection of these fields, Bossé, Ringler, Bayaga, Fountain, \& Young (2018) determined that mathematics learning shares many similarities with SLA. They developed the Mathematics Acquisition Framework (MAF) which determined four stages of mathematics learning: receiving, replicating, negotiating meaning, and producing mathematics. The MAF was then applied to investigate the validity of the framework on elementary through high school mathematics learners (Bossé, Bayaga, Fountain, \& Slate Young, (2017). This led to new avenues through which to analyze and understand student work in mathematics.

\section{Literature Review}

The background literature regarding employing the Mathematics Acquisition Framework (MAF) to investigate student understanding of fractions and fraction operations spans a number of fields including: fractions and decimals; primary and second language acquisition, mathematics learning, and mathematics acquisition.

\section{Fraction and Decimal Learning}

Numerous studies demonstrate that students struggle with both the understanding of, and the communication about, fractions and decimals (e.g., Jacob \& Nieder, 2009; Kallai \& Tzelgov, 2009; Meert, Grégoire, \& Noël, 2009; Muzheve \& Capraro, 2012; Opfer \& DeVries, 2008; Schneider \& Siegler, 2010) particularly in the dimensions of whole-number bias and number comparison paradigms (luculano \& Butterworth, 2011; Kara \& Incikabı, 2018). Thus far, the difficulties appear to be persistent and growing startlingly. For instance, while Opfer and DeVries (2008) suggest the challenge is with communication about fractions and decimals, Aliustaoğlu et al. (2018: 591) in exploring misconceptions of Fractions among elementary 6 th graders found three main difficulties including; parts-whole relation, representation on number line and comparison as well as operations. Aliustaoğlu et al. (2018: 591) laments that "students have misconceptions in terms of parts-whole relation in fractions...," ibid also evidenced that "...representation of fractions on the number line..." is a source of difficulty as with "...comparison of fractions and operations in fractions."

From a mathematical perspective, these difficulties may be ascribed to leaners recognizing fractions by their whole-number constituent parts (numerators and denominators) rather than as a relationship among the parts (or as a quotient) and recognizing decimal numbers as a concatenation of digits in different place values and not a single, valued, number. However, some have recognized these misunderstandings to be more sourced in issues regarding student cognition rather than in the mathematics itself (e.g., Bartelet, Ansari, Vaessen, \& Blomert, 2014; DeWolf, Rapp, Bassok, \& Holyoak, 2014; Lyons, Price, Vaessen, Blomert, \& Ansari1, 2014; Aliustaoğlu et al., 2018). A common theme arises from both the mathematical and cognitive perspectives: students strug-

\footnotetext{
b.* Corresponding Author: Neuro-Mathematics, Cognitive Computing \& Information Systems Privacy, Department of Mathematics, Science \& Technology Education (MSTE), University of Zululand, South Africa \& University of Cape Town, Department of Information Systems, Cape Town, South Africa. E-mail: BayagaA@unizulu.ac.za, Phone: +27 (0) 359026809.

appalachian State University. MELT Program Director, Department of Mathematical Sciences, NC, 28608, USA. E-mail: bossemj@appstate.edu 'Appalachian State University, Spanish and Linguistics, Graduate Director, Romance Languages, NC, 28608, USA. E-mail: fountainca@appstate.edu ${ }^{d}$ Coastal Carolina University, Spadoni College of Education, SC 29528, USA. E-mail: kathleen.lynch-davis@tamucc.edu

e East Carolina University, College of Education, Department of Mathematics, Science, and Instructional Technology Education, NC, 27858, USA. E-mail: prestonr@ecu.edu

EEast Carolina University, College of Education, Department of Mathematics, Science, and Instructional Technology Education, NC, 27858, USA. E-mail: adugwamfik@ecu.edu, Greenville, NC 28607
} 
gle with number comparison paradigms in the context of fractions and decimals. In the context of fractions, since students find comparing components of two fractions (a numerator with a numerator, a numerator with a denominator, or a denominator with a denominator) - whether or not leading to an accurate understanding - as easier and quicker than calculating the actual value of the fractions, they opt for the former (luculano \& Butterworth, 2011). While these studies agree that students struggle with both understanding and communicating about fractions and decimals, few have hypothesized a causal effect in either direction: poor understanding leading to poor communication or poor communication leading to poor understanding. Nevertheless, summarily, communication and understanding are interconnected.

\section{Primary and Second Language Acquisition}

Language acquisition is an innate, natural, predictable process occurring in normally developing children (Chomsky, 1957, 1959, 1964; Krashen \& Terrell 1983; Vygotsky, 1978). Primary language acquisition occurs through social interaction sans explicit instruction. According to Innatists, an innate Universal Grammar applicable to the acquisition of any language guides the acquisition of grammatical rules (Chomsky, 1957; Lightbrown \& Spada, 1999). Interactionists recognize that language acquisition occurs through processes of cognitive development and is tied to social development (Lightbrown \& Spada, 1999; Vygotsky, 1978). The process of primary language acquisition has similarities with both Piaget's (1979) processes of assimilation and accommodation and Bruner's (1966) three modes of a child's innate cognitive development: Enactive, Iconic, and Symbolic. Notably, Piaget and Bruner, along with numerous other applied linguists (e.g., Bailey, Madden, \& Krashen, 1974; Dulay \& Burt, 1973, 1974) recognize sequential stages of development from concrete to abstract and from social to academic. Similarly, Krashen and Terrell (1983) propose sequential stages through which children learn a primary language: pre-production, early production, early speech emergence, early intermediate, intermediate, and advanced.

Second language acquisition (SLA) is the learning of a language in addition to one's native language and typically occurs in a structured learning environment. Krashen's Monitor Model $(1977,1982)$ recognizes a distinction between language learning and language acquisition and that in classroom contexts both can occur simultaneously. Krashen's model defines a silent period as when learners are more focused on understanding and processing language rather than producing it and comprehensible input as language students simultaneously understand and that is slightly beyond their current level of full understanding. Swain (1985) and Swain and Lapkin (1995) assert that comprehensible output or language production that causes students to recognize gaps in their own knowledge, is also necessary for acquisition. Selinker $(1972,1992)$ proposes the concept of interlanguage, the learner's idiosyncratic and constantly evolving development and articulation of unique codes in the process of SLA.

Through different nomenclature, many have discussed the process of SLA learners' personally and interpersonally negotiating meaning in the language being acquired and among others in the learning environment (Christiansen, 1997; Garfinkel, 1967; Krashen, 1977, 1982; Krashen \& Terrell, 1983; Pica, 1996). Within SLA theory this negotiation of meaning is often restricted to the specific context of interpersonal communication and includes specific communicative strategies including confirmation checks, comprehension checks, and requests for clarification (Pica, 1987). In the framework in Bossé et al. (2018), this concept is extended to include both personal and interpersonal negotiation of meaning.
Cummins' $(1979,1984,1991)$ theories principally concern SLA by English Language Learners (ELLs), native speakers of non-English languages integrated into English-language school environments, who are in the process of acquiring a second language for the dual purposes of social and academic applications. To this end Cummins proposes Basic Interpersonal Communication Skills (BICS) and Cognitive Academic Language Proficiency (CALP) regarding social and academic language applications and proficiency respectively. According to Cummins' Linguistic Interdependence Theory (a.k.a., Common Underlying Proficiency (CUP)), SLA leads to increased competence in both parent and second languages, as literacy skills and knowledge are transferable into any language (1979, 1984, 1991). Altogether, Cummins' framework argues a bidirectional sequencing from a social language to an academic language and from a lighter to a heavier cognitive load.

Based in the work of many (e.g., Bartelet et al., 2014; DeWolf et al., 2014; Iuculano \& Butterworth, 2011; Jacob \& Nieder, 2009; Kallai \& Tzelgov, 2009; Lyons et al., 2014; Meert, Grégoire, \& Noël, 2009; Opfer \& DeVries, 2008; Schneider \& Siegler, 2010), characteristics associated with student learning of fractions and decimals can be recognized in SLA constructs. For instance, some characteristics of fraction and decimal learning can be seen as:

- progressing from concrete to symbolic to abstract (compare with Bruner (1966));

- initiated by students being unable to communicate about and produce ideas about fractions and decimals to students producing simple, then more advanced ideas (compare with Krashen and Terrell (1983));

- beginning by students mostly silently learning from the teacher leading to students experiencing concepts slightly above their immediate ability to comprehend (compare with Krashen $(1977,1982)$ ), grasping concepts regarding fractions and decimals for which they cannot adequately articulate (compare with Swain (1985) and Swain and Lapkin (1995)), and employing imprecise, vocabulary to articulate ideas commensurate with those with whom they are communicating;

- negotiating meaning of the fractions and decimals both personally and interpersonally (compare with Christiansen (1997), Krashen (1977, 1982), and Krashen and Terrell (1983) using confirmation checks, comprehension checks, and requests for clarification (compare with Pica (1987));

- developing from discussions that are informal, social, and cognitively undemanding to discussions that are formal, academic, and cognitively demanding (compare with Cummins (1979, 1984, 1991)).

\section{Mathematics Learning}

Van Hiele (1986) theorizes five levels of framework which are often utilized for mathematical learning with a specific focus on understanding geometry. While the five levels are not age dependent, they are sequential. Provided within the van Hiele model is a five-phase sequence through which students transition from any level to the following level; inquiry/information, directed orientation, explication, free orientation, and integration. The first of the five levels is visualization which is characterized by the ability to identify individual shapes, but cannot describe attributes of it. The second level termed as analysis, requires learners to prioritize the properties of a shape beyond the shape itself. The analysis level also requires learners to 
see the properties in isolation within the shape and not as a tool through which to compare shapes This second stage thus emphasizes the need to think in the context of connected properties rather than shapes. Abstraction which is the third level essentially requires learner to think in the context of connected properties rather than shapes. Abstraction is achieved by recognizing that certain combinations of these properties imply other ideas. The fourth level which is deduction requires the usage of deductive reasoning to create simple proofs and informally understand some aspects of non-Euclidean geometries. The last of the five levels is rigor. This stage requires some form of geometric understanding with some degree of sophistication and comparison of axiomatic systems.

Closely associated to Piaget's descriptions of assimilation and accommodation (1972), Dienes $(1960,1971)$ and Dienes and Golding (1971) proposed a six-stage Learning Cycle sequence describing how learners come to understand mathematics. The first three stages of Dienes' model include the stages of: free play, where early learners play with manipulatives or investigate ideas sans any predetermined rules; games, where the regularities discovered through free play become rules for games and further investigations; and searching for communalities, where common structures can be recognized across various games or ideas. These stages become cyclical and searching for communalities in one concept becomes play for a following concept.

The Learning Cycle is defined by representation, symbolization and formalization stages. While the representation requires learner to represent notions including games or ideas through some diagram or depiction, symbolization requires the learner to be able to condense representations. The symbolization stage however requires the need to turn notions into symbolic. The formalization requires learner to formalize findings into ordered structures similar to undefined terms, defined terms, axioms, and theorems.

Biggs and Collis' (1982) Structure of Observed Learning Outcomes (SOLO Taxonomy), also developed a sequence of levels in the learning of mathematics that students transition through. These levels or phases include: prestructural, where the learner does not understand issues within the task and attacks the problem inappropriately by oversimplifying a solution strategy; unistructural, where the learner focusses only on one aspect of the problem and does not recognize or utilize other aspects of the task; multistructural, where the learner addresses several relevant aspects of the task, but these aspects are disconnected and not synthesized; relational, where the learner coherently synthesizes relevant aspects into a conceptual whole; and extended abstract, where the learner abstracts and generalizes from the previous coherent whole into now topics of areas. The SOLO Taxonomy also recognizes intermediate stages between each sequential pair of stages.

Summarily, while there exist numerous conceptual agreements between the van Hiele, Dienes, and SOLO taxonomies, none may be more clearly recognized than that of the sequencing of levels. However, some have also recognized non-disjointedness between van Hiele levels (Burger \& Shaughnessy, 1986; Clements, Battista, \& Sarama, 2001; Fuys, Geddes, \& Tischler, 1988; Usiskin, 1982 as cited in Fuys, 1985).

As was the case in respect to SLA, characteristics associated with some mathematical learning theories can be recognized in student learning of fractions and decimals. For instance, some characteristics of fraction and decimal learning can be seen as:
- Progressing from basic recognition of fractions and decimals to recognizing properties associated with such and to being able to use and apply fractions and decimals (compare with Van Hiele (1986));

- Initially gaining understanding of fractions and decimals through concrete manipulatives leading to observing patterns and being able to represent fractions and decimals through manipulatives and symbolically represent manipulative constructs as fractions and decimals (compare with Dienes (1960, 1971) and Dienes and Golding (1971));

- Progressing from undeveloped understanding of fractions and decimals and oversimplifying arithmetic associated with such (leading to incorrect algorithms) to focussing one some aspects of fractions and decimals to the exclusion of other aspects and to connecting fractions and decimals to the coherent whole under rational numbers (compare with Biggs and Collis (1982)).

\section{Mathematic Acquisition}

Combining the notions of mathematics learning and SLA, Bossé et al. (2018) propose a sequence of stages, the Mathematics Acquisition Framework (MAF), defining the learning of mathematics including: receiving mathematics, replicating mathematics, negotiating meaning, and producing mathematics. These stages are characterized through student behaviors depicted in Figure 1.

Notably, in addition to defining behavioral characteristics associated with stages of mathematical learning, the MAF demonstrates transitions in a number of characteristic dimensions including transitioning from social to academic language, cognitively undemanding to demanding, teacher centric to student centric, and listening to reading and speaking to writing previously suggested by authors such as of Selinker $(1972,1992)$ and Krashen and Terrell (1983) and Cummins (1979, 1984, 1991).

\section{Objective of the Study}

The objective of the current study is to investigate grades five through seven students' comprehension of fractions and decimals through the lens of the MAF. This had the intent of providing new dimensions of explanations regarding student comprehension, communication, and misunderstandings in the context of fraction and decimal learning. Implications from these findings are considered later in this paper.

\section{Methodology}

Following the literature review and objective of the study, the research methodology employed in this study are case studies and discourse analysis (Bogden \& Biklen, 2003; Creswell, 2003; Miles \& Huberman, 1994; Wodak, 2009; Wodak \& Meyer, 2009). This study seeks to explore fifth, sixth, and seventh grades student understating of fractions and decimals through the lens of the Mathematics Acquisition Framework (MAF). In order to investigate this, five distinct scenarios of student-student or student-teacher interactions considering different contexts of fraction operations and understanding were observed. These included:

- Scenario 1: a sixth-grade student and his teacher consider division of fractions.

- Scenario 2: a fifth-grade student and her teacher consid- 


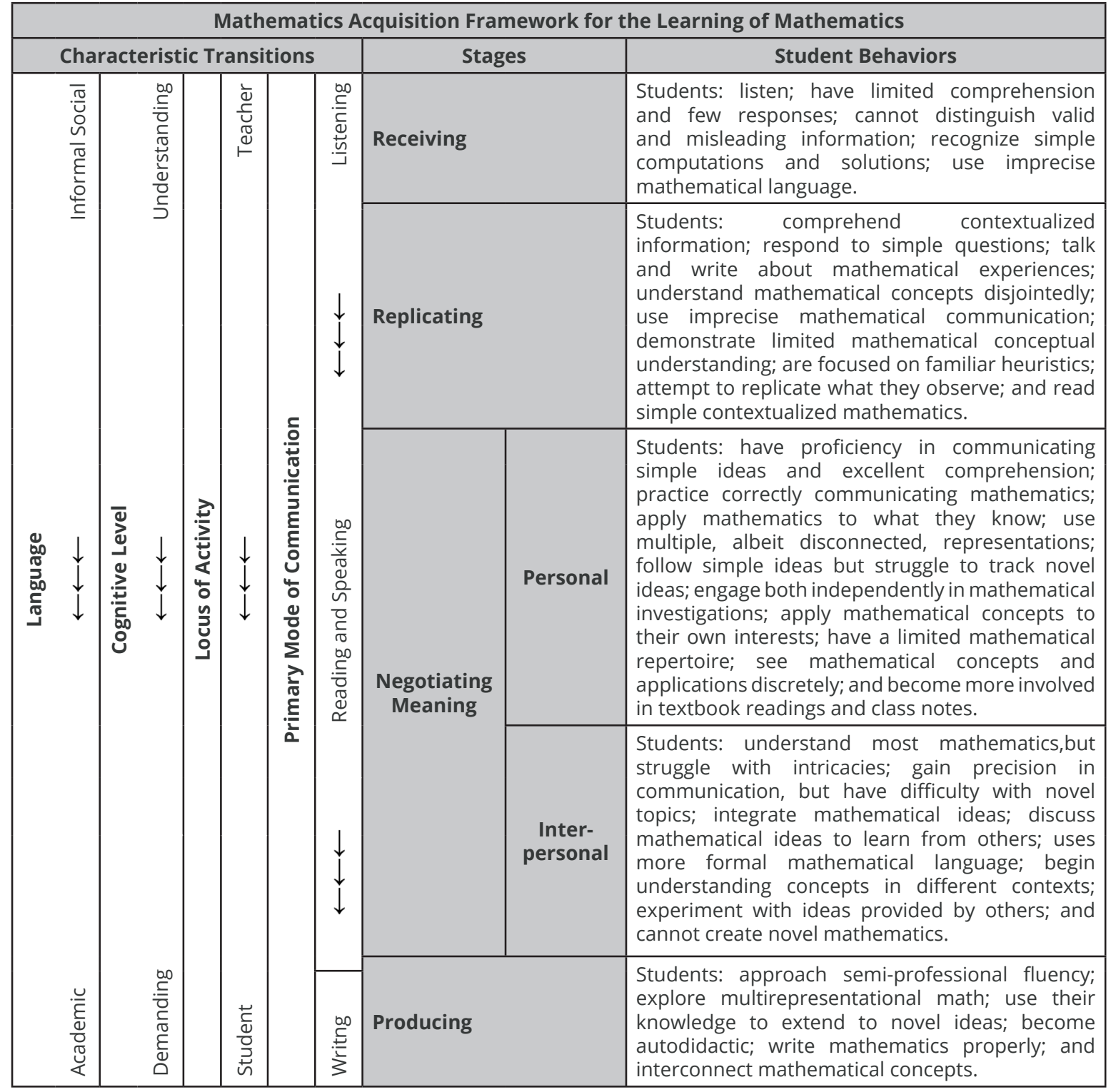

Figure 1. MAF Stages of Learning Mathematics [slightly edited from Bossé et al. (2018)].

er fractions and mixed numbers.

- Scenario 3: a group of sixth-grade students consider fraction simplification.

- Scenario 4: a group of seventh-grade students and their teacher consider connecting fractions and decimals.

- Scenario 5: a sixth-grade student and his teacher consider fractions and repeating and terminating decimals.

These scenarios were recorded in the students' and their respective teachers' regular classroom setting in one elementary school and two middle grades schools in the southeastern United States. These schools and teachers were selected for their convenience to the researcher; no other characteristics were considered. Videotaping occurred on days in which teachers were planning to cover various topics regarding fractions and decimals. Agreements were made to videotape any situations that arose during the class period.

To capture ideas within the data and to unpack meaning (Creswell, 2003), a systematic process of analysis was un- dertaken (Bogden \& Biklen, 2003). Videotapes were transcribed and copies of student work were merged with each transcript. Transcripts were independently analyzed through discourse analysis (Wodak, 2009; Wodak \& Meyer, 2009) to investigate student mathematical understanding, communication, and behaviors applicable to the MAF (Bossé, 2018). Common themes in the transcripts were characterized and labeled. Behaviors from the MAF were sought in the student transcripts for the stages of receiving, replicating, negotiating meaning, and producing mathematics. Codes were created regarding these MAF stages and additional codes were developed to observe characteristics regarding mathematics acquisition in respect to: a silent period, comprehensible input, comprehensible output, confirmation checks, comprehension checks, and requests for clarification. Coding structures were compared, differences reconciled, and refinements were made to initial codes. Check-coding (Miles \& Huberman, 1994) was employed to allow researchers to reach consensus on the analysis of all transcripts. Narrative summaries were developed and validated by the researchers against transcripts and student work to describe findings in the transcripts in respect to the MAF. 


\section{Results with Initial Analyses}

The results below are annotated transcripts from classroom situations in elementary and middle grades classrooms. Initial analysis follows each set of transcripts with particular attention given to division of fractions, fractions and mixed numbers, fraction simplification, connecting fractions and decimals, fractions and repeating and terminating decimals. These analyses consider student work, communication, and behavior through the perspective of the Mathematics Acquisition Framework (MAF).

Scenario 1: Division of fractions [In the following example, a sixth-grade student working through an example regarding division of fractions in a conversation with a teacher. The teacher has five years of teaching experience in this grade and a Masters Degree.]

Teacher: Please perform the operation.

Student: I think that I need to make an improper fraction first. Can be made into

Teacher: How did you do that?

Student: 2 times 2 plus 1.

Teacher: How do you know that works?

Student: That's how we do it. So, now we have $\frac{5}{2} \div \frac{1}{6}$

Then, we do keep-change-flip. We keep the first thing; change the division to a multiplication, and flip the last one. We do: $\frac{5}{2} \div \frac{1}{6}=\frac{5}{2} \times \frac{6}{1}$.

Teacher: How do you know that works?

Student: That's just how we do it. It gives us an

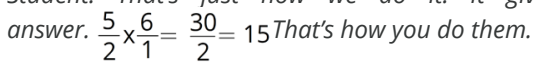

That's what we were told.

Teacher: So, what is the answer?

Student: 15.

Teacher: 15 what?

Student: Just 15.

Teacher: So, $\frac{1}{6}$ goes into fifteen times?

Student: I guess.

Teacher: What does the 15 mean?

Student: I don't understand. It's 15.

Teacher: When you do division, you get an answer.

Student: But I really don't know where it comes from. 15 is bigger than my numbers. We aren't supposed to get bigger numbers when we divide. Maybe that's why we change the division to multiplication: so we can get bigger numbers.

When prompted to explain how to convert a number into an improper fraction, the student responds with " 2 times 2 plus 1." However, the student is unable to explain why this is correct or anything more about the operation. When prompted to explain how he has arrived at the improper fraction $5 / 2$, he is unable to go further than to say simply, "That's how we do it."

The student's discourse shows a limited conceptual understanding division by fractions. He focuses on a familiar heuristic (keep-change-flip) to recall how to proceed with the operation and is able to employ such to perform the operation. However, when probed by the teacher, the stu- dent is unable to demonstrate deeper understanding of what it means to divide fractions; his responses include "That's how we do it" and "It gives us an answer." Altogether, this may evidence the student's use of imprecise mathematical communication.

The student's answers continue to demonstrate a lack of understanding into the meaning of the operations he is performing. Arithmetic steps are performed because "That's still how you do them... That's what we were told." While the student arrives at a correct answer, when prompted to confirm the meaning of " $\frac{1}{6}$ goes into $2 \frac{1}{2}$ fifteen times," the student replies with a noncommittal, "I guess."

When prompted directly to elaborate on what his answer means, he responds "I don't understand" and then "I really don't know where it comes from." Both answers may indicate that the student once more is relying on replicating operations that he has observed rather than working towards an understanding of what they mean. When asked whether or not division can result in a number larger than either of the operands, the student wonders if this may be "why we change the division to multiplication; so we can get bigger numbers." This exchange reveals limited conceptual understanding.

Analysis provides various clues that may indicate that the student is operating at a stage in which he is relying principally on memorized rules to replicate learned mathematical operations. The student states explicitly at several points that he is performing a given step or operation because this is the way in which he knows it should be done, but with no reflection on why this is the case and no demonstration of understanding the underlying concepts.

The student's behavior may present a number of characteristics from the descriptor of the MAF stages of receiving and replicating mathematics. From the stage of receiving mathematics, the student: demonstrates limited comprehension and provides few responses; cannot distinguish valid from misleading information; recognizes simple computations and solutions; and uses imprecise mathematical language. From the stage of replicating mathematics, the student: begins to comprehend contextualized information; responds to simple questions; talks and writes about mathematical experiences; understands mathematical concepts, albeit disjointedly; employs imprecise mathematical communication; demonstrates limited mathematical conceptual understanding; focuses on familiar heuristics; attempts to replicate what he observes from the teacher; and reads simple contextualized mathematics.

Most aspects attributable to the MAF stage of negotiating meaning are recognized in this student's work and behavior. Thus, by fulfilling behavioral numerous characteristics associated with receiving mathematics and fewer characteristics of replicating mathematics and almost none associated with negotiating meaning, this student is recognized as behaving and comprehending consistent with the stage of replicating mathematics.

Scenario 2: Fractions and Mixed Numbers [In this example, a fifth-grade student is working with a teacher on converting fractions to mixed numbers. The teacher has fifteen years of elementary school teaching experience and four years in this grade and a Masters Degree.]

Teacher: Convert $4 \frac{2}{3}$ to an improper fraction.

Student: 3 times 4 is 12 plus 2 is 14 . That gives $\frac{14}{3}$. 
Teacher: I see what you did. Can you tell me why that works?

Student: That's what we were told to do.

Teacher: Ok. Please convert $-4 \frac{2}{3}$ to a mixed number.

Student: 3 times -4 is -12 plus 2 is -10 . That makes $\frac{-10}{3}$.

Teacher: Let's look at some numbers on the number line. Can you show me where -4 is on the number line? [Student correctly points at a tick mark appropriate for -4] Great. Now show me -5. [Student correctly points at a tick mark appropriate for -5] Terrific.

Can you point to where $-4 \frac{1}{2}$ is?

[Student correctly points at a position centered between -4 and -5] Good. Where is $-4 \frac{2}{3}$ ?

[Student correctly points at a position between -4 and -5 and closer to -5] Great job. Let's add some tick marks to our number line. Let's put a tick mark at every $\frac{1}{3}$.

[Teacher constructs $\frac{1}{3}$ tick marks from 0 to -5$]$ Let's label

these: $-\frac{1}{3},-\frac{2}{3},-\frac{3}{3}$, which is $-1 ;-\frac{4}{3},-\frac{5}{3},-\frac{6}{3}$, which is

$-2 ;-\frac{7}{3},-\frac{8}{3},-\frac{9}{3}$, which is $-3 ;-\frac{10}{3},-\frac{11}{3},-\frac{12}{3}$, which is -4 ; and

$-\frac{13}{3},-\frac{14}{3},-\frac{15}{3}$, which is -5. Is everything right here?

Student: I think so.

Teacher: You said that $-4 \frac{2}{3}$ is $\frac{-10}{3}$. [Pointing to the number line] But $-4 \frac{2}{3}$ is way out here and $\frac{-10}{3}$ is right here.

Student: Those aren't the same. Let me see... 3 times -4 is -12 plus 2 is -10. Isn't that right?

Teacher: Yes, 3 times -4 plus 2 is -10. But is that correct? You just told me that $-4 \frac{2}{3}$ is not at the same place as $\frac{-10}{3}$

Student: They should be. Maybe the number line is wrong. [Teacher and student review the number line and the student finds no errors, but again recognizes that the two values are at different positions]

Teacher: Is $-4 \frac{2}{3}$ the same as $-4-\frac{2}{3}$ or $-4+\frac{2}{3}$ ?

Student: $-4+\frac{2}{3}$

Teacher: Why?

Student: Because $\frac{3}{2}$ is $\frac{1}{2}$ more than 3. And $-4 \frac{2}{3}$ is $\frac{2}{3}$ more

Teacher: But $-4 \frac{2}{3}$ is $\frac{2}{3}$ more than -4 in what direction?

Student: In that way. [Pointing toward negative values.]

Teacher: Ok. Point at -4. [Student complies.] Now go $\frac{2}{3}$

further in that direction. [Student lands on $-4 \frac{2}{3}$.] Great. So, that is $-4 \frac{2}{3}$ and not $\frac{-10}{3}$ ? Does that change how you

change $-4 \frac{2}{3}$ into an improper fraction?

Student: It's still 3 times -4 plus 2.

Teacher: Let's try something else. Is $-4 \frac{2}{3}$ the same as $\left(4 \frac{2}{3}\right) ?$
Student: What do you mean?

Teacher: Well, we know that -2 can be written as -(2). So, can $-4 \frac{2}{3}$ be written as $-\left(4 \frac{2}{3}\right)$ ?

Student: I don't know.

When prompted to explain how to convert a fraction in to a mixed number, the student can respond to a simple question and replicate what is observed to perform the operation correctly but cannot explain why her calculation works. She answers "That's what we were told to do."

The student's method of calculation fails when presented with a negative fraction and she is prompted to reconsider her thinking through the context a number line. However, with seemingly limited conceptual understanding and a disjointed understanding of mathematical concepts, she flounders when confronted with seemingly contradictory information.

The student is able to replicate what has been observed, " 3 times -4 is -12 plus 2 is -10 ", but seems unable to connect this calculation to the evidence from the number line, even with significant prompting. She suggests that perhaps something is wrong with the number line rather than with her own calculation, again demonstrating limited conceptual understanding. The final portion of the transcript continues to bear out this dynamic, with the student sticking to her memorized formula. When pushed to question her reasoning, her comprehension breaks down and she equivocates: "What do you mean?", and finally "I don't know."

This student's behavior seems to evidence some of characteristics from the MAF stages of receiving mathematics, a greater number of characteristics from replicating mathematics (we will not repeat them again, here) and no characteristics from negotiating meaning. Thus, this student is positioned in the stage of replicating mathematics.

Scenario 3: Fraction simplification [In this example, a group of sixth grade students are discussing the meaning of fraction simplification.]

Teacher: [Pointing to a clock on a wall] What part of an hour is 12 minutes?

Student 1: $\quad$ Twelve sixtieths, or 12 over 60.

Student 2: We can write that as $\frac{12}{60}$.

Student 3: $\quad$ Then we can simplify $\frac{12}{60}$ to $\frac{1}{5}$. [Students agree with the two answers]

$\frac{12}{50} \frac{1}{5}$

Student 4: But why do we want to change $\frac{12}{60}$ to $\frac{1}{5}$ ?

There are 60 minutes in one hour. Why change that?

Student 3: But $\frac{12}{60}$ is not simplified. The top and bottom have a

common factor of 12. We can't leave it like that. We need to write it like $\frac{1}{5}$.

Student 4: $\quad$ But if the two fractions are equal, does it matter how we write it?

Student 3: Yes, we are always supposed to simplify.

Student 1: But $\frac{12}{60}$ makes more sense. 12 minutes out of 60.1 know that $\frac{12}{60}$ is the same as $\frac{1}{5}$, but $\frac{1}{5}$ means 1 unit out of 5 . So thatone unitis a 12-minute unit. Whoeveruses 12 minutesasone unit? That doesn'teven make sense. $\frac{12}{60}$ is easier to understand when it comes to hours and minut 60

Student 2: Then what about seconds? If we were looking at the same question, 'what part of an hour is 12 minutes?' and we were really thinking about seconds, we would need to write 


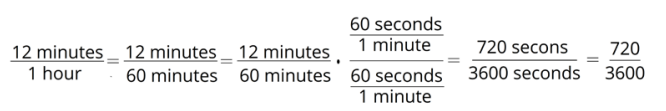

If we were looking at seconds, $\frac{720}{3600}$ would make more sense than .

Student 3: But $\frac{1}{5}$ is still simpler. It has smaller numbers.

Student 5: Wait a minute. $\frac{0.1}{0.5}$ has smaller numbers than, but I wouldn't say this that was simpler.

Student 4: [To the teacher] I'm confused. What do YOU want us to do?

This student discourse seemingly demonstrates students communicating with each other in order to negotiate the meaning of the mathematics. In addition to considering the meaning of the representation and applying an interpretation of the representation to the problem, the fractional representation is altered in order consider additional ideas. These students are comfortable moving beyond the simplest answer to discuss mathematical ideas and experiment with ideas from other students. Similar discourse continues as the students move beyond the original context of telling time to discuss the representation of fractions more globally through the employment of more formal (academic) mathematical language. These students are beginning to understand the concept of fractions in different contexts and are gaining precision in their mathematical communication. Beyond simply discussing the meaning of the fraction in question, the students collaboratively experiment with novel ideas.

In respect to the MAF, these students have seemingly surpassed receiving and replicating mathematics. They are no longer simply listening to the teacher or trying to mimic what they see. Student behaviors seem more in the realm of negotiating meaning. For instance, evidence exists of these students: possessing proficiency in communicating simple ideas with increased precision (formal, academic language) as they debate the meaning of simplification; demonstrating excellent comprehension, albeit struggling with particular conceptual intricacies and novel topics (e.g., as they multiply by a compound fraction equal to one); integrating mathematical concepts and applying mathematics to what they know and their own interests (e.g., as they apply fractions to time); and considering multiple mathematical representations (e.g., as they consider a fraction with a decimal numerator and denominator). Additionally, the students seem to be valuing communications with others as a significant experience within learning. While these students exhibit behavioral traits representing the stage of negotiating meaning, they do not seem to demonstrate behaviors commensurate with the stage of producing mathematics.

Scenario 4: Connecting fractions and decimals [In this example, a group of seventh grade students working with a teacher on concepts of fractions. The teacher has two years of experience in this grade and five more year of experience teaching sixth grade.]

$$
\text { Teacher: Find a fraction halfway between } \frac{1}{3} \text { and } \frac{1}{4} \text {. }
$$

Student 1: It is 0.29 .

Student 2: That is not a fraction.

Student 1: No problem, I'll just make that $\frac{29}{100}$. I like working with decimals more than fractions. So, I wrote $\frac{1}{3}$ as 0.33 and then $\frac{1}{4}$ as 0.25 . Halfway between the two decimals is 0.29 .

Student 2: I thought about the problem as doing averages and got $\frac{7}{24}$ for my answer. I added $\frac{1}{3}$ and $\frac{1}{4}$ by finding the common denominator of 12 . So, I really added $\frac{4}{12}+\frac{3}{12}$. That gave me $\frac{7}{12}$ which / divided by 2 to get $\frac{7}{24}$.

Student 3: I started out the same way, but I got something different for an answer. Since the fractions had a common denominator, I found the fraction halfway between. So, $\frac{1}{3}=\frac{4}{12}$ and $\frac{1}{4}=\frac{3}{12}$.

Since 12 is in both fractions, I just found the number halfway between 4 and 3. It's either 3.5 or $3 \frac{1}{2}$. So, my answer is $\frac{3}{\frac{1}{12}}$. Student 4: I don't think you are supposed to have a fraction within a fraction.

Student 5: I bet all three answers are really the same. I think they are all correct!

Student 2: The answers just don't look the same to me. Could we put them all in the same form to check?

Student 5: I can see that $\frac{7}{24}$ and $\frac{3 \frac{1}{2}}{12}$ are the same. Because the 12 is half of 24 and $3 \frac{1}{2}$ is half of 7 . They are in the same ratio.

Teacher: Excellent! Now, if the last two answers are equivalent, how could [Student 1] check to see if they are equivalent to his answer?

Student 1: We could convert the fractions to a decimal! would - it is much easier. Since we already know that both fractions are equal to $\frac{7}{24}$, convert it to a decimal by dividing
7 by

Student 5: That will work. Student 4: But $\frac{7}{24}$ is a repeating decimal and it doesn't equal 0.29. If is right, then [Student 1] did something wrong.

Teacher: But what if [Student 1] is right?

Student 5: I think the $\frac{7}{24}$ is right because it was equal to [Student 3's] answer. And it seemed like everything they did was right.

Teacher: That's a good enough theory. But can you find anything wrong with [Student 1's] reasoning?

Student 1: Would it make a difference if I rounded 1 when I converted it to a decimal?

Teacher: What do you think? [Asking the class] Did rounding make a difference? Could [Student 1] work with the decimals without rounding? Think about this tonight and if you have further ideas, we will explore them tomorrow.

In this exchange, the students consider and experiment with ideas proposed by others. Even when occasionally incorrect, the students' language is increasingly academic. The context of their communication is becoming cognitively demanding and the learning experience more student centric. Student communication shifts from verbal to symbolic, accentuated by more detailed verbal explanations. Comprehensible input takes the form of students not fully understanding the unusual explanations of other students and comprehensible output can be recognized through students being unable to explain completely their reasoning. At an increased pace, instances can be recognized where students are attempting to confirm their understanding, check their own comprehension, and seek clarification of ideas and understanding.

In respect to the Math Acquisition Framework, while the students' communication employs mathematical representations and recognize the power and value of each, 
the representations remain somewhat disconnected. For instance, although Student 1 claims to be able to convert fractions to decimals, he focusses more on decimals representations, gets an incorrect answer, and does not use his knowledge to check why the answer is incorrect. As the conceptual understanding of most of the students still reveals some gaps and misconceptions, great strides are being made within the groups to unify ideas and develop common understanding. For instance, Student 1 converts a fraction problem into a decimal problem, but converts $1 / 3$ to 0.33 . This is a round off error that is not caught by the other students. However, the students are together moving to the notion of calculating in their own form , even when it results in a fraction with a decimal or a mixed number in the numerator. Their focus is on communicating mathematics in an increasingly symbolic manner, employing mathematical representations to the best of their ability. The students follow most ideas they encounter, but still struggle with some ill-formed ideas posed by some of their fellow students. For instance, although they arrive at two different answers - one incorrect one in decimal form and a number of equivalent forms of a fractional answer, they struggle to reconcile the two different answers. Notably, the students in this scenario are now both communicating together and relying on the ideas of others to form and confirm their own understanding. The form of negotiating meaning is now interpersonal. The students do not rely simply on their own understanding; they are attempting to negotiate their own ideas with the ideas of the other students.

Scenario 5: Fractions and repeating and terminating decimals [In this example, a sixth-grade student working with a teacher on a notion regarding fractions and terminating and repeating fractions. The teacher has seven years teaching experience, all in this grade.]

Student: I think that I can tell if a fraction is a repeating or terminating decimal without doing the division.

Teacher: How?

Student. I started by looking at different numbers like 2, 3, 4 $5,6,7,8,9$, and 10 . I noticed that 2 terminated, 3 repeated, 4 terminated, 5 terminated, 6 repeated, 7 repeated, 8 terminated, 9 repeated, and 10 terminated?

Teacher: What do you mean that these numbers terminated or repeated? They are all just integers.

Student: No, I mean when they are in the denominator. Fractions with those denominators terminate or repeat. Teacher: Always?

Student: I think so.

Teacher: What about $\frac{3}{6}$ ? That terminates.

Student: I know! I mean when the numerator is 1. Like $\frac{1}{2}$, $\frac{1}{3}, \frac{1}{4}, \frac{1}{5}, \frac{1}{6}$ Teacher: But, does it have to be 1? If $\frac{1}{3}$ terminates, $\frac{2}{3}$ doesn't
also?

Student: Ok. You're trying to trick me. It's not what the numerator is. It's actually if the numerator and denominator are relatively prime. So, it can be any number in the numerator so long as they are relatively prime. That means that 1 will always work in the numerator if the denominator is anything other than 1.

Teacher: So, how can you tell if the fraction will produce a terminating or repeating decimal?

Student: I factor the denominators. If the factors in the denominator are only $2 \mathrm{~s}$ and $5 \mathrm{~s}$ or $2 \mathrm{~s}$ or $5 \mathrm{~s}-$ not quite sure how to say it - then the decimal will terminate. I think that you can look at this and even tell how many digits are in the decimal when it terminates. But, I'm still working on that idea.

Teacher: So, is it "2s and 5s" or "2s or 5s"?

Student: I knew that you were going to ask me that! Because I can have a denominator of 2, 4, and 8 terminate and 5 and 25 terminate, then I guess that I don't need both. So, I think it is "or". But I can have both. Like 10 is 2 and 5; 40 is 2 and 2 and 2 and 5; 50 is 2 and 5 and 5; and 100 is 2 and 2 and 5 and 5.

Teacher: And what about denominators like 3, 6, 15, and 35?

Student: If you factor those, you get $1 \times 3,2 \times 3,3 \times 5$, and $5 \times 7$. In each one you get factors other than $2 \mathrm{~s}$ and $5 \mathrm{~s}$.

Teacher: But 6 has a factor of 2?

Student: Yes, but it has a factor that is neither 2 nor 5.

Teacher: What about a denominator of 800 ?

Student: Um. That is $800=8 \times 100=8 \times 4 \times 25=8 \times 2 \times 2 \times 5 \times 5=$ $2 \times 2 \times 2 \times 2 \times 2 \times 5 \times 5$. All $2 \mathrm{~s}$ or $5 \mathrm{~s}$. that will terminate. As long as the numerator is relatively prime to 800 .

Teacher: Where did you find this idea?

Student: I didn't find it. I just played with numbers until I got it.

Teacher: Do you know why it works?

Student: I'm not sure yet, but I think that it has to do with those being the factors of 10 .

The student's language is gaining mathematical fluency. He uses terms such as numerator, denominator, factors and relatively prime. He rarely employs social language in his mathematical discussion and is becoming fluent in his academic language, communicating in a highly symbolic form. His initial hypothesis was born from investigating fractional and decimal form of rational numbers and interconnecting these ideas, thus denoting an ability to comfortably switch between representations. In developing his own theory regarding terminating and repeating fractions, he demonstrates that he is autodidactic and enjoys considering novel mathematical ideas and does not steer away from cognitively demanding tasks.

In respect to the MAF, this student is producing mathematics that is novel to him. Although his ideas are incomplete, his development of ideas is beyond what he has encountered in the class and demonstrates that he is in a stage of learning beyond most of his peers. His relationship with mathematics positive and somewhat recreational. Altogether, it seems that he is in the MAF state of producing mathematics.

\section{Discussions and Implications}

Recall that the present research sought to apply the MAF to investigate grades five through seve7 students' understanding of fractions and decimals. We examined how students transitioned and built understanding of principles and concepts through MAF. Following the methodology, we explored the of our findings to the background literature, we pay attention to MAF Expanse and appropriate curriculum. Some attention was devoted to growth through misunderstandings by which we mean locus of activity and mode of communication.

\section{MAF Expanse and Appropriate Curriculum}

The preceding transcripts and analyses demonstrate that students may be at very different stages in the MAF and the learning of mathematics, and this need not be a product of chronological development. Indeed, all of the students in this study were from grades five through seven; 
and yet, the entire spectrum of the MAF is recognized. This is consistent with some aspects of SLA as seen in the work of Selinker (1972,1992), Krashen and Terrell (1983), and Cummins $(1979,1984,1991)$ as demonstrated through the five research scenarios:

Scenario 1. While his informal mathematical articulations demonstrate his use of social language and that he has not yet moved to more academic language (Cummins, 1979, 1984, 1991), he has clearly passed beyond the silent period (Krashen, 1977, 1982). His task is one of simple, cognitively undemanding calculation and the mathematics problem is teacher generated and the learning is teacher centric (Cummins, 1979, 1984, 1991). The student is satisfied with repeating - to the best of his ability - what he has heard in the classroom. The student remains primarily a listener and speaks to repeat what he has previously heard (Krashen, 1977, 1982). The student experiences comprehensible input (Krashen, 1977, 1982) such as why the operations work as they do and comprehensive output (Swain, 1985; Swain \& Lapkin ,1995) such as being able to describe that the answer of 15 meant 15 of the divisors.

Scenario 2. This student uses informal (social) mathematical language and falls short of employing formal academic language and her task remains one of a simple, teacher generated (teacher centric), and cognitively undemanding calculation (Cummins, 1979, 1984, 1991). The student is primarily interested in repeating (as correctly as understood) what she has heard in the classroom (Krashen, 1977, 1982). She experiences comprehensible input regarding whether can be written as $-\left(4 \frac{2}{3}\right)$ (Krashen, 1977, 1982) and comprehensible output as she has some understanding but cannot explain her reasoning (Swain, 1985; Swain \& Lapkin, 1995). She employs an interlanguage in trying to explain whether $-4 \frac{2}{3}=-4+\left(-\frac{2}{3}\right)$ (Selinker, 1972, 1992). She does not yet appear to be at the stage of negotiating meaning; we do not yet see occurrences of confirmation checks, comprehension checks, and requests for clarification (Pica, 1987).

Scenario 3. The students have progressed from using informal, social language to formal academic language as their mathematical communication becomes more symbolic and written rather than singularly verbal and they are experimenting with increasingly cognitively demanding tasks, as they are investigating and generating definitions for fractions in simplified form and are not simply performing calculations (Cummins, 1979, 1984, 1991) The learning experience is becoming increasingly student centric (Cummins, 1979, 1984, 1991). While there remain moments of comprehensible input and output, the students' communication contains interlanguage as they talk about the "top" and "bottom" of the fraction and discuss the meaning of "simplified" (Krashen 1977, 1982; Selinker, 1972, 1992; Swain, 1985; Swain \& Lapkin, 1995). In the proicess of negotiating meaning, the students regularly employ confirmation checks, comprehension checks, and requests for clarification as they navigate concepts novel to themselves and to the others (Pica, 1987).

Scenario 4. The students' language is increasingly academic in nature and the context of their communication is becoming cognitively demanding and the learning experience more student centric (Cummins, 1979, 1984 1991). Comprehensible input takes the form of students not fully understanding the unusual explanations of other students and comprehensible output can be recognized through students being unable to explain completely their reasoning (Krashen, 1977, 1982; Swain, 1985; Swain \& Lapkin, 1995). Students have increased instances of students attempting to confirm their understanding, checking their own comprehension, and seeking clarification of ideas and understanding (Pica, 1987). The students are both communicating together and relying on the ideas of others to form and confirm their own understanding (Christiansen, 1997; Garfinkel, 1967; Krashen, 1977, 1982; Krashen \& Terrell, 1983; Pica, 1996).

Scenario 5.The student's language is increasingly academic in nature and he rarely employs social language in his mathematical discussion and he does not steer away from cognitively demanding tasks (Cummins, 1979, 1984, 1991).

\section{Summary of Scenarios}

The five scenarios provide evidence of students in different, and ascending sequential, stages in the MAF. Through this progress, evidence exists of transitioning from: social to academic language; cognitively undemanding to demanding; teacher centric to student centric; and listening to reading and speaking to writing. Although beyond the scope of this immediate study, it might be the case that students even in one seemingly homogeneous classroom may be at different stages in their learning. Therefore, even within a narrowly defined population, it is possible that some students are at one end of various spectra and others are at different ends. For instance, one student may be; focusing on listening; expecting learning to be centered on the teacher; using informal, social language; and struggling with cognitively undemanding tasks. Simultaneously, another student may be; focusing on writing mathematical ideas; expecting learning to either be through group interaction or be autodidactic; using formal, academic language; and engaging with cognitively demanding tasks as a growth through misunderstandings. Growth Through Misunderstandings

The recognition of mathematical errors and misunderstandings within student work take on different meanings in light of the MAF. Rather than simply considering student mathematical mistakes or misunderstandings as such, dimensions defined in the MAF make mathematical misunderstandings more contextualized in the learning process. Rather than faulty understanding, it can be recognized that students often experience: comprehensible input as they interact with information slightly beyond their understanding (Aliustaoğlu et al., 2018; Krashen, 1977, 1982; Krashen and Terrell, 1983); comprehensible output as they struggle to articulate what they know (Krashen, 1977, 1982; Krashen and Terrell, 1983); and interlanguage as they employ their incompletely formulated language and vocabulary (Selinker, 1972, 1992) to communicate their understanding. Indeed, these experiences and characterizations are quite idiosyncratic. Therefore, mathematical miscommunications and incomplete ideas can be recognized as natural aspects of learning rather than as mathematical misunderstandings.

The implication to this is to recognize mathematical errors and misunderstandings - particularly through student verbal articulation - as natural and positive within the process of learning. The idea that linguistic errors occur naturally on the path to acquiring language is well-studied and well-developed in the literature on both first and second language acquisition (Selinker, 1972, 1992), and given the connections made here between learning language and learning math, a parallel would not be unexpected. Quite possibly, then, student mathematical errors should be held as windows into student learning and not too quickly corrected. If we extend the parallel with SLA, the main goal would be to prevent these naturally occurring errors from becoming fossilized or internalized incorrectly by the learner as they move forward in the process of acquisition.

\section{Locus of Activity}

The transcripts in this study demonstrate cases in each 
of the stages of the MAF. In part, the cognitive level of the mathematics investigated and the locus of instruction define these stages. However, both of these dimensions may be more driven by the learner than by the classroom teacher. For instance, the students in this study in receiving and replicating mathematics consider the mathematics presented by the teacher at a low cognitive level. This does not mean that the teacher presents the mathematics at a low level; rather, the students can only consider whatever mathematics is presented at a low level. Conversely, the student in this study in the stage producing mathematics seems to consider more cognitively demanding mathematical concepts than what is presented by the teacher. Additionally, whether or not students desire to be the locus of instructional activity in the classroom, it seems that the students in this study in receiving and replicating mathematics would have a great deal of difficulty in this role and might find it both uncomfortable and inefficient in leaning in this role. Conversely, whether or not the teacher seeks to remain as the locus of instructional activity, the students in negotiating meaning and producing mathematics may seek for ways around the teacher in order to themselves become the center of their own learning.

This may raise a few implications. It is likely that the mathematical sophistication of a task is dependent on how cognitively demanding the students address the task. Students in lower stages may address all tasks at a low cognitive level and students in higher stages may begin from and embellish teacher-given tasks to being more cognitively demanding. On a parallel vein, it may not matter who the teacher determines to be the locus of activity. If the teacher endeavours to create a learner-centric instructional environment and the students are in the lowest stages of MAF, the environment may not affect learning. Conversely, if a teacher seeks to create a teacher-centric instructional environment for students in the highest stages of MAF, it is likely that these students will find opportunities to openly discuss the mathematics at hand, and thereby learn, or learn autodidactically. Thus, it may be that neither the mathematical content or the task nor the learning activity or the learning environment may affect either the cognitive load or the locus of activity that the students actually experience.

\section{Mode of Communication}

As defined in the MAF, the primary mode of communication in the states of learning transitions along the path:

listening $\longrightarrow \begin{aligned} & \text { speaking } \\ & \text { reading }\end{aligned} \longrightarrow \begin{aligned} & \text { reading } \\ & \text { speaking }\end{aligned} \longrightarrow$ writing

As seen in Scenarios 1 and 2, the students rely on listening to the teacher and attempting to replicate what they previously heard. At the other extreme, in Scenario 5, the student communicates the precision of his ideas in written form. In Scenarios 3 and 4, we recognize students employing different degrees of speaking and reading in order to come to understanding and communicate ideas.

Some implications to this may be that, although our goal in education may be to get students to write mathematics, we may be asking too much, too early of many students particularly when students are in early MAF stages. It may be that the introduction of writing assignments should only come after students are comfortable verbally communicating mathematical ideas.

While this study answers some questions, it may in turn raise many more. For instance, Van Hiele (1986) opines that, in order for a student to transition from any of the five stages (visualization; analysis; abstraction; deduction; and rigor) of the Van Hiele Model of Geometric Understanding to the subsequent stage, the student must experience five phases of attainment (information or inquiry; guided or directed orientation; explicitation; free orientation; and integration). Unfortunately, it is not yet known how to assist - or possibly accelerate - a student through to higher stages in the MAF. It might be as easy as treating a student in one stage as if he or she was in the subsequent stage. This is yet unknown.

\section{Further Implication}

The implications of this may be summed up in a seemingly trite phrase: one size does not fit all. With students at various stages of learning in the MAF and each stage having its particular nuances, it becomes apparent that no one size task or curriculum may fit all student needs. Nor does either group work (requiring communicative interaction), writing assignments (reflections or journaling), or demanding fully developed proper mathematics vocabulary - as appropriate as that may seem among reformed curricular recommendations - necessarily fit for students in the earlier stages. Thus, teachers must assess where students are in the MAF in order to provide the students developmentally appropriate learning activities.

\section{Conclusions}

Students, even among those from only a limited number of classes and even under the same teacher, can be at different mathematical learning stages in respect to the MAF. Some students employ informal/social language in their mathematical communication while others develop and use academic language. Some students are ready for, and thrive on, cognitively demanding tasks, while others are more comfortable with cognitively undemanding tasks. Some students are prepared for a teacher-centric learning environment, while others learn through student-centric environments and tasks. And some students learn through listening, others through reading and speaking, and still others through writing. Altogether, the variety of learning which occurs through transitioning through the MAF is significant. This may mean that teaching strategies should differ according to student learning needs.

The application of the MAF allows for more a positive interpretation of student errors, misunderstandings, and miscommunications. Rather than perceiving these in the negative, they can be seen as natural components to learning. This helps teachers and students experience a positive learning environment and may, in the end, address issues regarding math phobia.

The changing from teacher-centric to student-centric learning experiences may have far-reaching ramifications on future classrooms. As students move through the MAF, it is not the teacher who alters his or her teaching style; students naturally make this progression - or at least seek out these experiences. Teachers need only to teach to the needs of the students and this shift in locus of activity will occur naturally.

It is hoped that this investigation will inspire others to consider the MAF and student learning in greater detail. The authors hope that soon others will discover pedagogical applications that will assist students to both address student needs at every stage of the MAF and assist them to move through the MAF to higher stages of learning.

\section{References}

Aliustaoğlu, F., Tunab, A and Biber A.C. (2018). Misconceptions of Sixth Grade Secondary School Students on Fractions. International Electronic Journal of Elementary Education, 10(5), pp 591-599. 
Bailey, N., Madden, C., \& Krashen, S. (1974). Is there a 'natural sequence' in adult second language learning? Language Learning, 24, 235-243.

Barnett, C., Goldenstein, D., \& Jackson, B. (Eds.) (1994). Fractions, decimals, ratios, \& percents: Hard to teach and hard to learn? Mathematics teaching cases. Portsmouth, $\mathrm{NH} .:$ Heinemann.

Bartelet, D., Ansari, D., Vaessen A., \& Blomert, A. (2014) Cognitive subtypes of mathematics learning difficulties in primary education. Research in Developmental Disabilities 35 (2014) 657-670.

Biggs, J. B., \& Collis, K. F. (1982). Evaluating the quality of learning - The SOLO taxonomy. New York: Academic Press.

Bogdan, R. C., \& Biklen, S. K. (2003). Qualitative research for education: An introduction to theories and methods (4th ed.). Boston: Allyn and Bacon.

Burger, W. F., \& Shaughnessy, J. M. (1986). Characterizing the van Hiele levels of development in geometry. Journal for Research in Mathematics Education, 17, $31-48$.

Bruner, J. S. (1966). Toward a Theory of Instruction, Cambridge, Mass.: Belkapp Press

Chomsky, N. (1957). Syntactic Structures. The Hague: Mouton.

Chomsky, N. (1959). A review of B. F. Skinner's Verbal Behavior. Language, 35(1), 26-58.

Chomsky, N. (1964). Current Issues in Linguistic Theory. The Hague: Mouton.

Christiansen, I. (1997). When negotiation of meaning is also negotiation of task: Analysis of the communication in an applied mathematics high school course. Educational Studies in Mathematics 34(1), 1-25.

Clements, D. H., Battista, M. T., \& Sarama, J. (2001). Logo and geometry. Journal for Research in Mathematics Education, Monograph Series, 10.

Creswell, W. J. (2003). Research design: Qualitative, quantitative and mixed methods approaches (2nd ed.). London: Sage Publications.

Cummins, J. (1979). Cognitive/academic language proficiency, linguistic interdependence, the optimum age question and some other matters. Working Papers on Bilingualism, 19, 121-129.

Cummins, J. (1984). Bilingualism and Special Education: Issues in Assessment and Pedagogy. Clevedon, England: Multilingual Matters.

Cummins, J. (1991). Language development and academic learning. In L. Malavé \& G. Duquette (Eds.) Language, culture and cognition. (pp. 161-175). Clevedon, England: Multilingual Matters.

DeWolf, M., Rapp, M., Bassok, M., \& Holyoak, K. J. (2014) Semantic alignment of fractions and decimals with discrete versus continuous entities: A textbook analysis. Proceedings of the Annual Meeting of the Cognitive Science Society, 36, 2133- 2138.

Dienes, Z. P. (1960). Building up Mathematics. London: Hutchinson Education Ltd.

Dienes, Z. P. (1971). An example of the passage from the concrete to the manipulation of formal systems. Educational Studies in Mathematics, 3 (3/4), 337-352.
Dienes, Z. P., \& Golding, E. W. (1971). Approach to Modern Mathematics. New York: Herder and Herder Co.

Dulay, H., \& Burt, M. (1973). Should we teach children syntax? Language Learning, 23, 245-258.

Dulay, H., \& Burt, M. (1974). Natural sequences in child second language acquisition. Language Learning, 24, 37-53.

Fuys, D. (1985). Van Hiele levels of thinking in geometry. Education and Urban Society, 17(4), 447-462.

Fuys, D., Geddes, D., \& Tischler, R. (1988). The van Hiele model of thinking in geometry among adolescents. Journal for Research in Mathematics Education. Monograph 3.

Garfinkel, H. (1967). Studies in Ethnomethodology. Englewood Cliffs, NJ: Prentice- Hall.

Jacob, S. N., \& Nieder, A. (2009). Notation-independent representation of fractions in the human parietal cortex. The Journal of Neuroscience, 29(14), 46524657.

Kara, F., \& Incikabı, L. (2018). Sixth Grade Students' Skills of Using Multiple Representations in Addition and Substraction perations in Fractions. International Electronic Journal of Elementary Education, 10(4), 463-474.

Kallai, A.Y., \& Tzelgov, J. (2009). A generalized fraction: An entity smaller than one of the mental number line. Journal of Experimental Psychology: Human Perception and Performance, 35(6), 1845-1864.

Krashen, S. (1977). Some issues relating to the monitor model. In H. D. Brown, C. Yorio \& R. Crymes (Eds.) Teaching and learning english as a second language: Trends in research and practice. (pp. 144-158) Washington: TESOL.

Krashen, S. D. (1982). Principles and Practice in Second Language Acquisition. Oxford: Pergamon.

Krashen, S. D., \& Terrell, T. (1983). The Natural Approach: Language Acquisition in the Classroom. London: Prentice Hall Europe.

Lightbrown, P. M., \& Spada, N. (1999). How languages are learned [2nded.]. Oxford: Oxford University Press.

Luculano, T., \& Butterworth, B. (2011). Rapid communication Understanding the real value of fractions and decimals. The Quarterly Journal of Experimental Psychology, 64 (11), 2088-2098.

Lyons, I. M., Price, G. R., Vaessen, A, Blomert, L., \& Ansari, A. (2014). Numerical predictors of arithmetic success in grades 1-6. Developmental Science, $X$, pp 1-11.

Meert, G., Grégoire, J., \& Noël, M.-P. (2009). Rational numbers: Componential versus holistic representation of fractions in a magnitude comparison task. The Quarterly Journal of Experimental Psychology, 62(8), 1598-1616.

Miles, M. B., \& Huberman, M. N. (1994). Qualitative data analysis: an expanded sourcebook. Thousand Oaks, $C A$ : Sage.

Muzheve, M. T., \& Capraro, R. M. (2012). An exploration of the role natural language and idiosyncratic representations in teaching how to convert among fractions, decimals, and percents. Journal of Mathematical Behavior, 31(1), 1-14 
Opfer, J. E., \& DeVries, J. M. (2008). Representational change and magnitude estimation: Why young children can make more accurate salary comparisons than adults. Cognition, 108, 843-849.

Pica, T. (1987). Second language acquisition, social interaction, and the classroom, Applied Linguistics, 8, 3-21.

Pica, T. (1996). The essential role of negotiation in the communicative classroom. Japan Association of Language Teaching Journal, 18 (2), 241-268

Piaget, J (1979). "Comments on Vygotsky's critical remarks". Archives de Psychologie. 47 (183): 237-249.

Schneider, M., \& Siegler, R. S. (2010). Representations of the magnitudes of fractions. Journal of Experimental Psychology: Human Perception and Performance, 36, 1227-1238.

Selinker, L . (1992). Rediscovering Interlanguage. London: Longman.

Selinker, L. (1972). Interlanguage. International Review of Applied Linguistics, 10, 209-231.

Swain, M. (1985). Communicative competence: some roles of comprehensible input and comprehensible output in its development. In S. Gass, S. and C. Madden, (Eds.), Input in second language acquisition. Rowley, MA: Newbury House.

Swain, M., \& Lapkin, S. (1995). Problems in output and the cognitive processes they generate: a step towards second language learning. Applied Linguistics, 16(3), 371-391.

Usiskin, Z. (1996). Mathematics as a language. In Communication in Mathematics: K-12 and Beyond 1996 Yearbook. Edited by Elliott, P.C., \& Kenney, M.J. Reston, VA: NCTM.

Van Hiele, P. M. (1986). Structure and insight: A theory of Mathematics Education. Orlando, FL: Academic Press.

Vygotsky, L. S. (1978). Mind in society. Cambridge, MA: Harvard University Press.

Wodak, R. (2009). Aspects of Critical Discourse Analysis. London. Sage Publications.

Wodak, R., \& Meyer, M. (2009). Methods of Critical Discourse Analysis. London and New York. Longman. 